\title{
BMJ Open Feasibility and acceptability of breath research in primary care: a prospective, cross-sectional, observational study
}

\author{
Georgia Woodfield (D , , ${ }^{1}$ laria Belluomo, ${ }^{1}$ Piers R Boshier, ${ }^{1}$ Annabelle Waller, ${ }^{1}$ \\ Maya Fayyad, ${ }^{1}$ Christian von Wagner (D) , ${ }^{2}$ Amanda J Cross, ${ }^{3}$ George B Hanna ${ }^{1}$
}

To cite: Woodfield G, Belluomo I, Boshier PR, et al. Feasibility and acceptability of breath research in primary care: a prospective, cross-sectional, observational study. BMJ Open 2021;11:e044691. doi:10.1136/ bmjopen-2020-044691

- Prepublication history and supplemental material for this paper is available online. To view these files, please visit the journal online (http://dx.doi. org/10.1136/bmjopen-2020044691).

Received 12 September 2020 Revised 02 January 2021 Accepted 23 March 2021

Check for updates

(C) Author(s) (or their employer(s)) 2021. Re-use permitted under CC BY-NC. No commercial re-use. See rights and permissions. Published by BMJ.

${ }^{1}$ Department of Surgery and Cancer, Imperial College London, London, UK

${ }^{2}$ Institute of Epidemiology and Health Care, University College London, London, UK

${ }^{3}$ School of Public Health, Imperial College London, London, UK

Correspondence to Professor George B Hanna; g.hanna@imperial.ac.uk

\section{ABSTRACT}

Objectives To examine the feasibility and acceptability of breath research in primary care.

Design Non-randomised, prospective, mixed-methods cross-sectional observational study.

Setting Twenty-six urban primary care practices.

Participants 1002 patients aged 18-90 years with gastrointestinal symptoms.

Main outcome measures During the first 6 months of the study (phase 1), feasibility of patient enrolment using faceto-face, telephone or SMS-messaging (Short Message Service) enrolment strategies, as well as processes for breath testing at local primary care practices, were evaluated. A mixed-method iterative study design was adopted and outcomes evaluated using weekly Plan-DoStudy-Act cycles, focus groups and general practitioner (GP) questionnaires.

During the second 6 months of the study (phase 2), patient and GP acceptability of the breath test and testing process was assessed using questionnaires. In addition a 'single practice' recruitment model was compared with a 'hub and spoke' centralised recruitment model with regards to enrolment ability and patient acceptability.

Throughout the study feasibility of the collection of a large number of breath samples by clinical staff over multiple study sites was evaluated and quantified by the analysis of these samples using mass spectrometry.

Results 1002 patients were recruited within 192 sampling days. Both 'single practice' and 'hub and spoke' recruitment models were effective with an average of 5.3 and 4.3 patients accrued per day, respectively. The 'hub and spoke' model with SMS messaging was the most efficient combined method of patient accrual. Acceptability of the test was high among both patients and GPs. The methodology for collection, handling and analysis of breath samples was effective, with $95 \%$ of samples meeting quality criteria.

Conclusions Large-scale breath testing in primary care was feasible and acceptable. This study provides a practical framework to guide the design of Phase III trials examining the performance of breath testing in primary care.

\section{BACKGROUND}

Late diagnosis is a common feature of patients with gastrointestinal cancers and is associated with poor survival. ${ }^{12}$ Patients

\section{Strengths and limitations of this study}

- This is the largest ever breath testing study to be conducted within a primary care setting.

- The study recruited 1002 patients from primary care for breath testing using face-to-face, telephone and SMS-messaging enrolment strategies, in patients with gastrointestinal symptoms.

- The study explored models for breath sampling including single-site sampling at local primary care practices, as well as a centralised breath sampling strategy.

- The study assessed feasibility and acceptability of breath testing in patients with gastrointestinal symptoms from both a patient and a healthcare provider perspective, using a concurrent iterative mixed methods approach.

- This study did not assess diagnostic accuracy of the breath test for diagnosis of gastrointestinal cancers or ascertain the optimum place a breath test may have in existing diagnostic pathways, where both of these factors could affect feasibility and acceptability of a future breath test.

with early oesophageal, gastric, pancreatic or colorectal cancers often have non-specific symptoms typical of many common benign conditions. ${ }^{3} 4$ In comparison, 'red flag' symptoms linked to gastrointestinal cancers often indicate advanced incurable disease. ${ }^{5-7}$ Currently only patients with 'red flag' symptoms are urgently referred for diagnostic testing. ${ }^{89}$ Opening existing diagnostic pathways to patients with non-specific symptoms can however lead to potentially harmful overinvestigation that would consume National Health Service resources and cause unnecessary anxiety for the majority of patients who do not have cancer.

There remains, therefore, an unmet clinical need to establish accurate, accessible and affordable methods for early gastrointestinal cancer detection that are not reliant on traditional approaches that are invasive and expensive. The non-invasive detection of 
disease markers within human breath is a promising field of research that has the opportunity to transform our ability to detect cancers of unmet need. Breath testing has the ideal characteristics of a triage test for early cancer detection, being non-invasive and acceptable to patients. A breath test could serve as a community triage test, for patients with vague symptoms that may be associated with cancer, but do not currently meet ('red flag') criteria for investigation. A breath test would support general practitioners (GPs) as well as other healthcare providers to determine which patients most warrant referral using existing gastrointestinal cancer diagnostic pathways.

The test is based on the detection of volatile organic compounds (VOCs) within exhaled breath. VOCs are produced by humans as a result of both normal and abnormal metabolism. Once released into the systemic circulation, VOCs may travel to the lungs where they are excreted in exhaled breath. ${ }^{10}$ A systematic review of breath testing for cancer identified distinctive VOCs signals for different tumour sites with pooled sensitivity and specificity of $79 \%$ and $89 \%$, respectively (including lung, breast, gastrointestinal, head and neck, prostate and gynaecological tumours). ${ }^{11}$ Studies of different gastrointestinal tumour sites also showed different VOC biomarkers for oesophagogastric, pancreatic and colorectal cancers, providing the opportunity for a single breath test to diagnose different cancers based on their unique VOC signature, in a similar way to a single blood draw being used to assess for multiple diseases. ${ }^{12-15}$

Before large-scale primary care trials can occur, there is a need to evaluate different recruitment and engagement strategies to determine the feasibility and acceptability of the test. Historically, despite an ever-increasing need for high-quality research in primary care, adequate patient recruitment has been a critical barrier. ${ }^{16}{ }^{17}$ Reasons for this include dependence on financial incentives, ${ }^{18}$ inadequate infrastructure, time constraints within busy practices, lack of buy-in and failure to show adequate recognition for those contributing to the study. ${ }^{17}{ }^{19}$ Mitigation of these challenges is essential if GPs are to continue contributing to research and clinical trials.

The primary aim of this study was to inform the design of future large-scale studies by examining the feasibility of different recruitment and engagement strategies for breath testing in primary care. The secondary aim was to understand the acceptability of the breath test among both patients and GPs.

\section{METHODOLOGY}

\section{Study setting and patients}

The Methodological Approaches towards a Gastrointestinal Cancer Breath Test (MAGIC) study was a crosssectional observational breath-testing study based in 26 primary care practices within Central and Northwest London (online supplemental file S1). Practices were approached based on previous research participation or expression of interest. Breath sampling was coordinated and performed by clinical study officers (CSOs) from the National Institute of Health Research (NIHR) clinical research network North West London and local practice nurses.

The recruitment target was 1000 patients over 12 months (260 sampling days). Study eligibility criteria were patients aged 18-90 years old who were suffering from upper or lower gastrointestinal symptoms. Gastrointestinal symptoms included all 2 weeks wait (2WW) and urgent referral symptoms within National Institute for Health and Care Excellence guidelines. ${ }^{89}$ GPs and trial staff were provided with a list of all eligible gastrointestinal symptoms (online supplemental file S2-S4). Patients with chronic symptoms (lasting $>2$ months) were included only if they had ongoing requirement for pharmacological control. Patient eligibility was assessed by GPs at the time of a routine face-to-face appointment or from review of electronic medical records.

All subjects provided informed written consent prior to participation.

\section{Methods of recruitment}

To evaluate different methods of recruitment the study was divided in to two phases. During phase 1 (29 November 2016 to 26 May 2017) 'single practice' breath sampling was conducted at 16 primary care practices. Breath sampling occurred at two practices concurrently for 2 weeks before equipment and staff were relocated to two new practices.

During phase 2 (7 November 2017 to 14 June 2018) a 'hub and spoke model' was trialled. Seven practices that were part of the Central London Healthcare GP federation recruited concurrently by referring all patients to a single central practice for breath testing (Marylebone Health Centre), regardless of the patients' registered GP practice. Local 'single practice' breath testing was also continued at three practices during phase 2 recruitment.

\section{Methods of patient engagement}

Patients who met eligibility criteria entered the study by one of four methods: face-to-face same day; face-toface prebooking; telephoning or SMS (text) messaging. In phase 1, all four methods of patient enrolment were assessed, whereas in phase 2, SMS messaging was used exclusively.

For face-to-face enrolment, GPs identified and approached potentially eligible patients at the time of routine consultation. Those willing to participate in the study were enrolled either on the same day (face-to-face same day) or at an agreed future time and date (face-toface prebooking).

The telephone and SMS recruitment models involved manual or automated searching of practice electronic medical records to identify potentially eligible patients (online supplemental files S5 and S6). Identified patients were contacted via either telephone or SMS message, inviting them to participate in the study. Patients who received an SMS message had previously agreed to this 
form of communication with their healthcare provider and were required to respond 'yes' to request a telephone call-back. Patients were telephoned by the practice receptionist who briefly explained the purpose and requirements of the study. Patients agreeing to participate were offered an appointment in a designated breath-testing clinic. The purpose of the study was carefully explained to patients both verbally and within an approved patient information sheet prior to enrolment. All patients were told that the breath test will potentially be used in the future to detect gastrointestinal cancers, but that the current study was intended to investigate the process and feasibility of breath testing only.

\section{Feasibility and acceptability of breath testing}

Feasibility and acceptability of breath testing in primary care among staff and patients was assessed using a mixedmethods approach.

In phase 1, it was important to identify and overcome in real time, barriers to breath testing in primary care based on challenges faced by staff administering the test. Field notes were used to document weekly events and to inform Plan-Do-Study-Act (PDSA) cycles. 'Plan' involved creation of a weekly recruitment strategy accounting for surgery-specific considerations, for example, half-days and room availability. 'Do' consisted of sampling, for which investigators (GW and the lead CSO) had daily contact with CSOs and recorded verbal feedback of any recruitment, sampling or logistical problems and their solutions. 'Study' was weekly review of this process. 'Act' was achieved by planning with CSOs how to overcome barriers for the subsequent week.

A teleconference and subsequent focus group were held with CSOs after one and 6 months of study initiation, respectively. These events were used to explore feasibility and acceptability of the testing process, from the viewpoint of the CSOs. The teleconference was an unstructured CSO-led conversation and feedback session (six CSOs and GW). The focus group (12 CSOs: 1 male, 11 females and GW) consisted of a brief presentation summarising study progress, then a minimally structured CSO-led discussion regarding perceived feasibility, acceptability, challenges and mitigation strategies, lasting 1 hour. All CSOs working on the study were invited by email to participate, therefore representing a convenience sample, at St Mary's Hospital London. The focus group was led by GW (study lead) who was known to participants. The focus group was video recorded and later transcribed. Acquired transcripts were subject to thematic analysis to identify primary themes. ${ }^{20}$ Representative quotes were selected manually to illustrate the themes identified. Finally, questionnaires were given to participating GPs to complete anonymously. Likert style questions focused on their opinions around study design and logistics, with open questions regarding the remit of breath testing in primary care (online supplemental file S7).
In phase 2, patient acceptability questionnaires were used to explore opinions about the process, equipment and concept of the breath test (online supplemental file S8). The design was influenced by other established questionnaires, using Likert scales. ${ }^{21} 22$

\section{Breath sampling and quality control}

Prior to enrolling patients, staff were required to attend one of three training days at either St Mary's hospital (October or November 2016) or Marylebone Health Centre (November 2017). During these sessions staff received study-specific training regarding patient enrolment and breath sample collection and handling.

Patients were not required to follow any specific conditions, such as fasting, prior to breath sampling. Before collecting breath samples CSOs explained the breath test procedure to patients. Breath samples were collected using the ReCIVA CE-marked handheld breath sampling device (Owlstone, Medical, Cambridge, UK). The standardised method for breath sampling using this device has been previously published. ${ }^{23}$ Breath $(500 \mathrm{~mL})$ was collected on to a single thermal desorption (TD) tube (Markes International, Llantrisant, UK) packed with Carbograph/Tenax sorbent. The three remaining TD tube positions within the ReCIVA device were occupied by blank tubes. Inhaled ambient air was decontaminated by passing through an activated charcoal filtration column before being entrained via a tightly fitting facemask.

To maintain breath sampling quality, CSOs were trained to monitor expiratory volume and $\mathrm{CO}_{2}$ traces during testing. If the traces were interrupted, they optimised the mask seal, or restarted the software, documenting any problems encountered.

Sealed TD tubes were stored within an airtight container and couriered weekly between the laboratory at St Mary's hospital (Imperial College London) and the primary care practices. All samples and clinical data were anonymised with no ability to retrospectively trace patients.

TD tubes were analysed using proton transfer reaction time of flight mass spectrometry (PTR-ToF-MS; Ionicon Analytik GmbH, Innsbruck, Austria) or gas chromatography mass spectrometry (GC-MS; Agilent Technologies, Cheshire, UK) in accordance with previously developed standardised methods. ${ }^{24} 25$ Standard quality control procedures for instruments and equipment were implemented $^{24}{ }^{26}$ (online supplemental file S9). Breath samples within TD tubes were evaluated for quality based on detected levels of acetone and isoprene (online supplemental file S10). Acceptable thresholds for acetone and isoprene were dependent on analytical platform.

Finally, quantitative data were collected throughout the study recording TD tube transport, processing and analysis times as well as the content and quality of breath VOCs.

\section{Patient and public involvement}

Patients, nurses and GPs were engaged in the study design, recruitment methodology and running of this study on a 


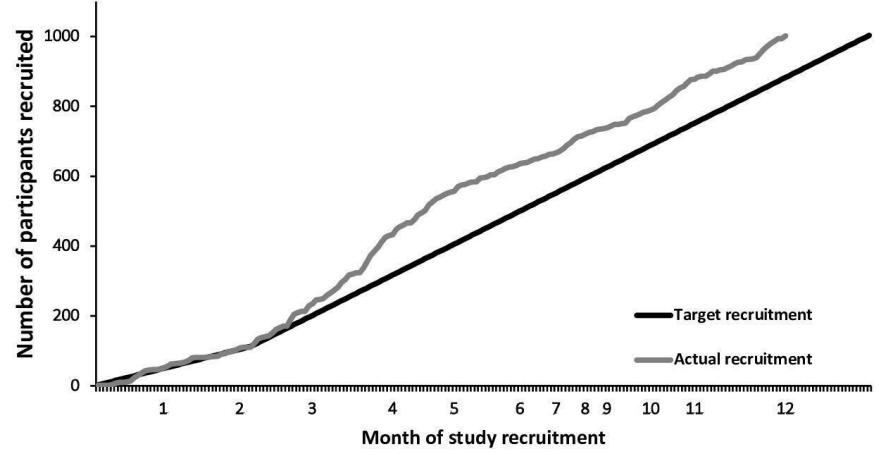

Figure 1 Total MAGIC study recruitment. Each point on $\mathrm{x}$ axis represents intended sampling days only, hence uneven month distribution. MAGIC, Methodological Approaches towards a Gastrointestinal Cancer Breath Test. daily basis. Their experiences and preferences were the material used for weekly PDSA cycles, and more formal feedback was gathered from questionnaires and the focus group, guiding changes in methodology.

\section{RESULTS}

Recruitment was successful, reaching 1002 patients within 192 of 260 allocated sampling days (figure 1). Patient demographics and reported symptoms are presented in table 1. Verification of patients against eligibility criteria found concordance in 998 (96.6\%) cases. Four patients who were aged $>90$ year at the time of breath sampling breached eligibility criteria and were excluded.

Table 1 Demographics of eligible patients and characteristics of reported symptoms

\begin{tabular}{|c|c|c|c|}
\hline & $\begin{array}{l}\text { All patients } \\
\mathrm{N}=998\end{array}$ & $\begin{array}{l}\text { Phase } 1 \\
\mathrm{~N}=633\end{array}$ & $\begin{array}{l}\text { Phase } 2 \\
\mathrm{~N}=365\end{array}$ \\
\hline Age, years (range) & $59.7(18-90)$ & $59.3(18-90)$ & $58.8(18-90)$ \\
\hline \multicolumn{4}{|l|}{ Sex } \\
\hline Male & $409(41 \%)$ & $244(39 \%)$ & $165(45 \%)$ \\
\hline Female & $578(58 \%)$ & $385(61 \%)$ & $193(53 \%)$ \\
\hline Unrecorded & $11(1 \%)$ & $4(1 \%)$ & $7(2 \%)$ \\
\hline \multicolumn{4}{|l|}{ Race } \\
\hline Caucasian & $599(60 \%)$ & $335(53 \%)$ & $264(72 \%)$ \\
\hline Asian/Asian British & $189(19 \%)$ & $161(25 \%)$ & $28(8 \%)$ \\
\hline Black/African/Caribbean/Black British & $100(10 \%)$ & $73(12 \%)$ & $27(7 \%)$ \\
\hline Arab & $30(3 \%)$ & $17(3 \%)$ & $13(4 \%)$ \\
\hline Other & $60(6 \%)$ & $31(5 \%)$ & $29(8 \%)$ \\
\hline Unrecorded & $20(2 \%)$ & $16(3 \%)$ & $4(1 \%)$ \\
\hline Current smoker & $120(12 \%)$ & $72(11 \%)$ & $48(13 \%)$ \\
\hline Oral intake $<5$ hours & $798(80 \%)$ & $458(72 \%)$ & 340 (93\%) \\
\hline \multicolumn{4}{|l|}{ Duration of main symptom(s) } \\
\hline Today & $234(25 \%)$ & $139(22 \%)$ & $95(26 \%)$ \\
\hline Recently (within 8 weeks) & $351(38 \%)$ & $241(38 \%)$ & $110(30 \%)$ \\
\hline Chronic & $172(19 \%)$ & $112(18 \%)$ & $60(16 \%)$ \\
\hline Unrecorded & $241(26 \%)$ & $141(22 \%)$ & $100(28 \%)$ \\
\hline Patients reporting & $\mathrm{N}=921^{*}$ & $\mathrm{~N}=586$ & $\mathrm{~N}=335$ \\
\hline$\geq 1$ UGI symptom & $822(89 \%)$ & $533(91 \%)$ & $289(86 \%)$ \\
\hline$\geq 1$ LGI symptom & $608(66 \%)$ & $397(68 \%)$ & $211(63 \%)$ \\
\hline Single symptom reported & $165(18 \%)$ & $110(19 \%)$ & $55(16 \%)$ \\
\hline UGI symptoms(s) warranting urgent referral† & $152(17 \%)$ & $98(17 \%)$ & $54(16 \%)$ \\
\hline UGI symptom(s) warranting non-urgent referral† & $306(33 \%)$ & $199(34 \%)$ & $107(32 \%)$ \\
\hline LGI symptoms(s) warranting urgent referral† & $289(31 \%)$ & $178(30 \%)$ & $111(33 \%)$ \\
\hline
\end{tabular}

*Symptoms were unrecorded in 77 patients, however for 44 of these patients the 'duration of symptoms' was recorded. †Symptom(s) warranting urgent direct access endoscopic or radiological referral or urgent 2WW referral as per NICE guidelines for UGI (including pancreatic cancer) and LGI cancer. ${ }^{89}$

LGI, lower gastrointestinal; NICE, National Institute for Health and Care Excellence; UGI, upper gastrointestinal; 2WW, 2 week wait. 
Table 2 Patient engagement methods for phase 1

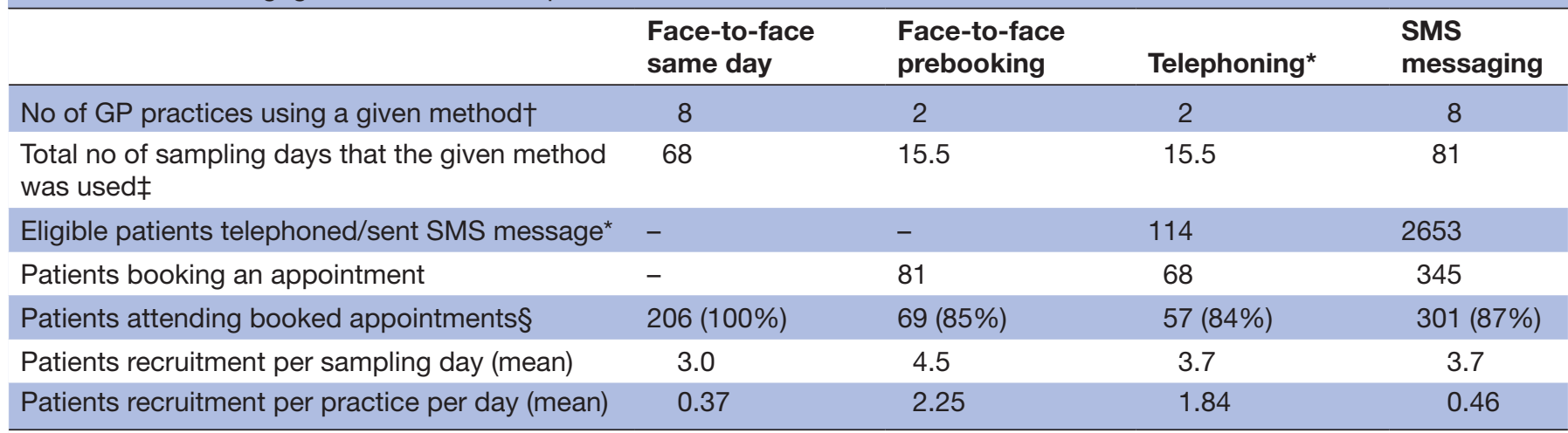

*Unanswered/wrong number calls are unrecorded.

†A total to 16 practices contributed to recruitment during phase 1, four practices used a combination of face-to-face enrolment and either telephoning or SMS messaging, hence they are counted twice for the purposes of this table.

‡Recruitment could occur at two GP practices at any one time, hence, for the purposes of this table only, sampling days could be counted twice, hence total is $>192$ days.

$\S$ Values in parenthesis represent percentage of patients agreeing to breath testing who actually completed the test.

GP, general practitioner; SMS, Short Message Service.

\section{Methods of patient engagement}

Four methods of patient engagement were assessed in phase 1: face-to-face same day, face-to-face prebooking, telephoning and SMS messaging. During phase 2, SMS messaging was used exclusively for initial patient engagement. Details of patient accrual for each of the four engagement methods are presented in table 2.

The percentage of patients who completed the breath test after agreeing to be tested ranged from $84 \%$ to $100 \%$ depending of the method of initial engagement. Where patients either opted or were required to prebook a breath test, test completion rates tended to be lower reflecting a 'drop-out' rate of between $15 \%$ and $18 \%$.

\section{Methods of recruitment}

During phase 1 ('single practice' recruitment), 633 eligible patients were recruited over a total of 119 sampling days (average 5.3 patients per day). In phase 2 ('hub and spoke' and 'single practice' recruitment), 365 eligible patients were recruited over a total of 73 sampling days (average 5.0 patients per day). For the hub and spoke' model alone, recruitment averaged 4.3 patients

Table 3 Patient recruitment methods, phase 1 and phase 2 combined

\begin{tabular}{lcc}
\hline & $\begin{array}{l}\text { Single } \\
\text { practice } \\
\text { model }\end{array}$ & $\begin{array}{l}\text { Hub and } \\
\text { spoke } \\
\text { model }\end{array}$ \\
\hline Number of GP practices & 19 & 7 \\
\hline Total number of sampling days & 168 & 24 \\
\hline Total number of patients recruited & 895 & 103 \\
\hline Patient recruitment per day (mean) & 5.3 & 4.3 \\
$\begin{array}{l}\text { Patient recruitment per practice per } \\
\text { day (mean) }\end{array}$ & 0.28 & 0.61 \\
\hline
\end{tabular}

GP, general practitioner. per day (table 3). During phase 2, patient recruitment using the 'single practice' model was maintained at 5.3 patients per day.

When normalised to number of GP practices contributing to patient recruitment for each recruitment method within both phase 1 and phase 2, the average number of patients accrued per centre per day was higher for the 'hub and spoke' compared with 'single practice' method (0.61 vs 0.28 ) (table 3 ).

\section{Feasibility and acceptability of the breath testing process Patient recruitment}

Twenty-five healthcare professionals were successfully trained to sample breath, showing feasibility of this task for a wide range of operators. Feedback obtained from field notes and the CSO-led teleconference and focus group regarding the advantages and challenges of recruitment and engagement methods are summarised in table 4 .

Patient accrual rate was initially low, due to a number of recognised challenges: inconsistent referral of patients, inefficient use of CSO time, technical problems and mismatch of CSO and GP schedules. Full details of reported challenges to breath testing and mitigation strategies are provided as an online supplemental file S11. Following iterative refinement of the approach to patient accrual and breath testing there was a marked acceleration in recruitment during months two to five of the study (figure 1). This was likely due to improved CSO familiarity with equipment and study procedures over time, as well as the dynamic and adaptable study design, driven by weekly PDSA cycles, which allowed early recognition of problems and development of solutions. Dedicated breath testing clinics were set up to sample all patients who had entered the study via face-to-face prebooking, phone or SMS recruitment. This was an efficient and effective strategy that enabled testing for up to 12 patients per half day (table 4 ). With only one site 
Table 4 Feedback obtained from focus group and field notes

\begin{tabular}{ll}
\hline Face to face same-day/face-to-face prebooking \\
Positive \\
Method of recruitment open to all GP practices \\
No requirement for administrative staff \\
Face-to-face same-day: convenient for patients as no separate visit needed \\
Fege-to-face prebooking: allowed patients to be brought back at a time convenient for them \\
Negative & Reliant on GP engagement: CSOs having to 'remind GPs 2-3 times per morning' with some GPs admitting to \\
& 'forgetting to send in patients'. \\
Telephoning recruitment in smaller (less busy) practices & Inefficient: CSOs present all day for a mean yield of approximately three patients. \\
Positive & Method of recruitment open to all GP practices \\
Negative & Appointments available for up to 12 patients per half day 'breath clinic' \\
& Requires support of administrative staff to contact patients \\
& Administrative staff only able to give general information about study when calling patients \\
& Cost of telephoning (including staff time)
\end{tabular}

\section{SMS messaging}

\begin{tabular}{|c|c|c|}
\hline Positive & \multicolumn{2}{|c|}{$\begin{array}{l}\text { More efficient than telephone booking as patients who were telephoned had already expressed interest in being } \\
\text { involved in breath testing by responding to SMS message. This led to higher booking rates. } \\
\text { Appointments available for up to } 12 \text { patients per half day 'breath clinic' } \\
\text { Patient initial identification not reliant on attendance to GP. } \\
\text { Potentially more convenient for patients. }\end{array}$} \\
\hline \multirow[t]{2}{*}{ Negative } & \multicolumn{2}{|c|}{$\begin{array}{l}\text { Only open to GP practices with ability to send SMS messages to patients. } \\
\text { Proportion of patients who were ultimately tested was lower than for other enrolment methods (approximately } 10 \% \\
\text { uptake). } \\
\text { Identification of patients based on database searching has the potential to be less reliable and could vary between } \\
\text { different practices. } \\
\text { Requires support of administrative staff to contact patients. } \\
\text { Administrative staff only able to give general information about study when calling patients. } \\
\text { Cost of telephoning (including staff time). }\end{array}$} \\
\hline & Single practice & Hub and spoke \\
\hline Positive & $\begin{array}{l}\text { Patient convenience in attending own GP practice } \\
\text { Allows for face-to-face same-day enrolment }\end{array}$ & $\begin{array}{l}\text { Broader recruitment cohort } \\
\text { Fewer CSOs required (two for single hub): reduced CSO } \\
\text { training time and potential improved consistency and } \\
\text { quality of sampling. } \\
\text { More flexibility for patients wanting to book an } \\
\text { appointment and more efficient for CSOs to collect } \\
\text { samples. }\end{array}$ \\
\hline Negative & $\begin{array}{l}\text { Narrower recruitment cohort } \\
\text { Larger no of CSOs required, with less efficient use of their } \\
\text { time }\end{array}$ & $\begin{array}{l}\text { Some patients may either not wish to or be able to travel } \\
\text { to the central hub for testing } \\
\text { Allocation of appointments between multiple practices, } \\
\text { meaning that there was a requirement for a central } \\
\text { booking system }\end{array}$ \\
\hline
\end{tabular}

CSO, clinical study officer; GP, general practitioner; SMS, Short Message Service.

being used for sampling, fewer staff and less equipment was required, transport and logistics were easier to coordinate, and bulk collection lowered courier costs. After recruitment acceleration, the rate then stabilised and was maintained, even after the integration of the 'hub and spoke' model. This finding reveals that testing patients at a centralised site does not negatively affect recruitment. It also indicates that a dynamic and responsive study design may be an effective strategy for primary care studies like this, as recruitment was maintained despite using 26 practices all with different environments and clinic schedules (online supplemental file S11). These findings and the lessons learnt during recruitment led to the development of a flowchart of recommendations for improving recruitment in primary care studies (online supplemental file S12).

Acceptability of the test

\section{GP perspective}

Twenty-one GPs, from 10 of the 26 participating practices, answered the GP specific questionnaire. Nine out of 10 GPs reported that asking patients to participate, sending them through to the $\mathrm{CSO} /$ nurse, answering patient questions and general logistics of breath testing was 'very easy' or "easy" Perceived barriers to participation were 'time constraints' (clinical staff and patients') and the fact that this was a research study where individual patients were not intended to directly benefit from test results. All GP 
Table 5 Summary of patient acceptability questionnaire responses $(n=365$, phase 2$)$

\begin{tabular}{|c|c|c|c|c|c|}
\hline & $\begin{array}{l}\text { Very easy/very } \\
\text { comfortable }\end{array}$ & $\begin{array}{l}\text { Easy/ } \\
\text { comfortable }\end{array}$ & $\begin{array}{l}\text { Difficult/ } \\
\text { uncomfortable }\end{array}$ & $\begin{array}{l}\text { Very difficult/ } \\
\text { very uncomfortable }\end{array}$ & $\begin{array}{l}\text { Not } \\
\text { applicable }\end{array}$ \\
\hline $\begin{array}{l}\text { How easy was it to do the breath test? } \\
\text { (\%) }\end{array}$ & 79 & 20 & 1 & 0 & 0 \\
\hline $\begin{array}{l}\text { How did you find the experience of } \\
\text { holding the device during the test? (\%) }\end{array}$ & 42 & 55 & 2 & 0 & 1 \\
\hline $\begin{array}{l}\text { Would you be comfortable to do the } \\
\text { breath test again, if recommended to by } \\
\text { a doctor? (\%) }\end{array}$ & Took too long & $\begin{array}{l}\text { Acceptable } \\
\text { amount of time }\end{array}$ & Too quick & - & $\begin{array}{l}\text { Not } \\
\text { applicable }\end{array}$ \\
\hline \multirow{2}{*}{$\begin{array}{l}\text { What did you think about the time it } \\
\text { took to give a breath sample? (\%) }\end{array}$} & 2 & 95 & 3 & - & 0 \\
\hline & $\begin{array}{l}\text { Strongly } \\
\text { encourage }\end{array}$ & Encourage & Discourage & Strongly discourage & $\begin{array}{l}\text { Not } \\
\text { applicable }\end{array}$ \\
\hline $\begin{array}{l}\text { Would you encourage family and friends } \\
\text { who were offered a breath test to } \\
\text { complete it? (\%) }\end{array}$ & 59 & 39 & 0 & 0 & 2 \\
\hline \multicolumn{6}{|c|}{ Free text comments regarding overall sampling experience } \\
\hline \multicolumn{6}{|c|}{$\begin{array}{l}\text { 'Nothing to improve because there is nothing to it. It's nice' } \\
\text { 'I found the breath test to be extremely satisfactory, I am happy to participate in more research' } \\
\text { 'I found it fine as it is. And, it was a rather nice experience. I liked it.' }\end{array}$} \\
\hline
\end{tabular}

respondents reported that they had 'no concerns about the study' from their patients. GPs' opinions about the potential place of a breath test in clinical practice are detailed in online supplemental file S13.

\section{Patient perspective}

During phase 2, all 365 eligible patients completed acceptability questionnaires, providing overwhelmingly positive feedback for the breath test (table 5). Of those patients recruited using the 'hub and spoke model', only one $(0.3 \%)$ commented that they found travelling to a different GP practice inconvenient. The breath test was also acceptable to patients with a wide variety of medical problems, including 197 patients with either asthma, chronic obstructive pulmonary disease, or other lung diseases. Thirteen $(3.5 \%)$ patients suggested that a handsfree breath sampler would be preferable. This comment was offset by others saying they liked being 'in full control of the mask'. Despite CSOs being asked to inform patients that masks were sterile and single-use, and to open masks in front of patients, three $(0.8 \%)$ patients enquired about sterility of the mask. This therefore reflected an explanation/execution issue rather than an equipment issue.

\section{Breath sampling and quality control}

Although there were minimal patient related limitations, technical issues with sampling equipment were reported. A summary of themes regarding feasibility and acceptability of the sampling process is detailed in online supplemental file S14. Problems were frequently solved by restarting or updating the computer software for the ReCIVA device. When such measures failed, CSOs resorted to collecting breath as 'timed samples' where patients were asked to breathe into the ReCIVA for $5 \mathrm{~min}$ without using the device's software. This meant that the volume and flow rate of breath sampling was uncontrolled. 'Timed samples' accounted for 87 (13.7\%) of the 633 eligible samples collected during phase 1 and occurred primarily at the start of study when CSOs lacked experience using the ReCIVA. In comparison during phase 2 of the study, when study logistics and methodology had been optimised, only 7 (1.9\%) 'timed samples' were collected out of a total of 365 eligible samples. During the final 6 weeks of sampling there were no reported equipment failures. CSOs did not report any issues with TD tube storage or transport.

On average breath samples were analysed within 2.8 (range 0-11) days of collection. Eighty-three (13\%) samples collected during phase 1 of the study were stored at $-80^{\circ} \mathrm{C}$ for up to 13 days before analysis as a result of instrument downtime. The collection to analysis time was therefore prolonged for these samples, averaging 8.8 (range 3-14) days. There was no instrument downtime in phase 2 of this study, therefore, no storage of breath samples at $-80^{\circ} \mathrm{C}$ was required. Twenty-six phase 2 GC-MS samples were lost due to a GC-MS instrumental error.

Breath samples were analysed by PTR-ToF-MS $(n=316)$ and GC-MS ( $n=23)$ in Phase-2 of MAGIC. Three hundred $(95 \%)$ of those analysed by PTR-ToF-MS and $21(91 \%)$ of those analysed by GC-MS were deemed to contain adequate quantities of breath. 


\section{DISCUSSION}

The analysis of VOCs within exhaled breath offers a noninvasive approach to the detection of a number of diseases including gastrointestinal cancers. ${ }^{11}$ Such a test could be offered in primary care to patients presenting with nonspecific symptoms that do not meet existing guidelines for referral. However, before a large phase-III clinical trial can be conducted in primary care, it is necessary to first understand the feasibility and acceptability of the breath test in this setting. The current study was designed to evaluate different recruitment and engagement strategies for breath testing in primary care. Phase 1 evaluated different engagement methods in addition to discovering optimum organisation and implementation strategies. Phase 2 was used to evaluate patient acceptability of the test, with the rationale that acceptability could only be assessed after optimisation of delivery during phase 1 . The emphasis on patient recruitment during phase 1 meant a greater number of patients were accrued during this period. This was not however felt to be detrimental to the findings of phase 2 .

This study showed that both sampling in a single GP practice as well as the centralised hub-and-spoke model of referral were viable and acceptable to patients and study staff. It was hypothesised that attendance and attitudes towards the breath test may be negatively affected by having to travel to a central location. However in this study it was observed that centralising breath testing reduced staffing and equipment requirements with no discernible negative impact on patient feedback. Transport and logistics were easier from one single location, and bulk collection lowered courier costs. In terms of organisation within primary care services, a breath test is comparable to a blood test. If we consider breath testing as a complete service, where the testing, results and any referrals to secondary care were managed as a streamlined pathway, we could draw comparisons to other centralised services such as diabetes care, which lowers costs. ${ }^{27}$ The hub-and-spoke model evaluated in phase 2 of this study explored the concept of testing patients in a central location, in this instance a GP practice. Finding may be applicable to other centralised testing centres such as diagnostic centres and hospitals.

Four methods of engagement were evaluated in phase 1. Each was deemed to be feasible and acceptable. The method of enrolment adopted in future trials and ultimately clinical practice will largely reflect the intended purpose of the test (eg, triaging symptomatic patients or screening asymptomatic populations). SMS messaging, and to a lesser extent telephoning, has the potential to reach large numbers of patients. However, as highlighted, this approach may only result in $10 \%-50 \%$ of patients being assessed, akin to population screening. Alternatively, opportune identification of patients by GPs may be more representative of a targeted triage test that could be used as an adjunct to the existing $2 \mathrm{WW}$ referral pathway. A flow chart of how to optimise patient recruitment in primary care studies, taken from lessons learnt during this study, is detailed in online supplemental file S12.

The breath test received almost universal acceptance. The overwhelming majority of patients found the test easy to complete, with wide representation from patients of different age, gender, comorbidity and ethnicity. Selection bias may, however, have influenced findings given that enrolled patients were those who were more likely to seek medical attention and engage with medical research. Although gastrointestinal cancers are more common in men, a greater number of women participated in this study, possibly influencing results. Dutch data reported that women are $18 \%$ more likely to consult their GP than men after adjustment for gender-specific factors. ${ }^{28}{ }^{29}$ The focus group was also predominantly female, potentially influencing results.

During the last 6 weeks of the study, after optimisation of sampling methodology and consolidation of staff training, technical failures of breath collection were eliminated. Analysis of breath samples within a central laboratory was achieved with established quality control procedures to ensure instrumental consistency. ${ }^{11}$ Ninety-five per cent of all samples that were analysed were deemed to contain adequate quantities of breath. For implementation of breath testing on a wider scale, standardisation across different laboratories is required. Alternatively point of care devices could be developed to streamline the analysis and receipt of test results.

It has been previously highlighted that time and financial pressures can be a major barrier to conducting highquality research in primary care. ${ }^{18}$ Importantly GPs and research staff were supportive of conducting breath research in primary care. Patient enrolment and sampling using SMS messaging and a central sampling hub helped to reduce the workload of GPs as they were no longer responsible for identifying and approaching potentially eligible patients. Access to research nurses from the NIHR likewise helped to minimise additional burdens to GP services during study recruitment. GP practices also received a modest financial incentive, as they were remunerated for every patient recruited by the NIHR, at a rate of 220 and $£ 25$ per patient for phases 1 and 2, respectively. This may have encouraged participation and provided some recognition for the additional workload caused by the study. However, these factors may not apply outside of the research setting, potentially influencing acceptability of breath testing to GPs, particularly where responsibility for implementing testing, interpreting and actioning results may fall to them.

No previous study has sought to define how breath testing can be successfully integrated into primary care with the engagement of both patients and clinical stakeholders. Strengths of this study were its two phased design and concurrent iterative mixed methods approach. Limitations were that the demographics and views of patients who did not respond/ agree to breath testing were not recorded. Such information would have been valuable in determining barriers to patient's participation. The fact that this was a research study without 
direct clinical benefit to patients may have contributed to patients declining to participate. The rate of uptake of the test within the target population, and influencing factors, while not the focus of the current study, should nevertheless be clarified in future studies. A broader assessment of the opinions of key stakeholders may have established greater consensus as to the role of the breath test in clinical practice as well as challenges to its adoption. Patients were not required to follow any specific conditions prior to the breath test, as there are currently no evidence based guidelines for sampling breath in clinical practice. This means that the study may not be fully representative of a future breath testing pathway. Finally, this study was not designed to assess the diagnostic performance of the breath test.

This study determined that it was feasible to collect and conduct high-quality analysis of large numbers of breath samples from primary care. This provides encouraging new evidence to support the use of wide-scale breath testing in this setting. In parallel to existing and ongoing diagnostic accuracy and standardisation studies, breath testing appears to be a feasible and acceptable and an accurate method of assessing patients with unexplained gastrointestinal symptoms. This study provides a practical framework to guide the design of larger phase 3 trials examining the performance of the proposed breath test in primary care. The design and methodology can also be applied to other large-scale primary care studies, particularly as it provides valuable insights as to how to optimise recruitment in this well-known challenging research sector.

Acknowledgements The authors wish to acknowledge the invaluable input and expertise of Professor Wendy Atkin, who supervised this project until she very sadly passed away in December 2018. The authors wish to thank Lucinda Hetherington (Northwest London Clinical Research Network) who was the lead clinical study officer for the MAGIC study and coordinated the study at multiple primary care practices.

Contributors All authors made substantial contributions to the work; specifically GW and GBH conceived the work with IB, PRB, CvW and AJC making substantial contributions to the design, CvW in particular with regards to the patient acceptability questionnaire. GW planned and executed the study process. GW, IB, $\mathrm{PRB}, \mathrm{AW}$ and MF contributed to data acquisition and analysis, with interpretation overseen by CvW, AJC and GBH. GW, IB and PRB drafted the first manuscript version, where all authors revised it critically and then approved the final version. All authors can account for the integrity of this work.

Funding The research was supported by awards from Rosetrees and Stoneygate Trusts via Imperial College Charity (grant number 171812) and by infrastructure funding from the NIHR London In Vitro Diagnostic Cooperative programme (grant number P67522). Piers R Boshier was funded by the NIHR (grant number not applicable).

Disclaimer The views expressed are those of the author(s) and not necessarily those of the NHS, the NIHR or the Department of Health.

Competing interests None declared.

Patient consent for publication Not required.

Ethics approval Ethical approval was obtained from the Camden \& Kings Cross Research Ethics Committee (14/L0/1136).

Provenance and peer review Not commissioned; externally peer reviewed.

Data availability statement Data are available on reasonable request. Relevant anonymised data are included in the article or uploaded as online supplemental information. Additional anonymised data are available on reasonable request.

Supplemental material This content has been supplied by the author(s). It has not been vetted by BMJ Publishing Group Limited (BMJ) and may not have been peer-reviewed. Any opinions or recommendations discussed are solely those of the author(s) and are not endorsed by BMJ. BMJ disclaims all liability and responsibility arising from any reliance placed on the content. Where the content includes any translated material, BMJ does not warrant the accuracy and reliability of the translations (including but not limited to local regulations, clinical guidelines, terminology, drug names and drug dosages), and is not responsible for any error and/or omissions arising from translation and adaptation or otherwise.

Open access This is an open access article distributed in accordance with the Creative Commons Attribution Non Commercial (CC BY-NC 4.0) license, which permits others to distribute, remix, adapt, build upon this work non-commercially, and license their derivative works on different terms, provided the original work is properly cited, appropriate credit is given, any changes made indicated, and the use is non-commercial. See: http://creativecommons.org/licenses/by-nc/4.0/.

\section{ORCID iDs}

Georgia Woodfield http://orcid.org/0000-0003-4958-6842

Christian von Wagner http://orcid.org/0000-0002-7971-0691

\section{REFERENCES}

1 Cancer Research UK. Bowel cancer survival statistics - by stage, 2018. Available: https://www.cancerresearchuk.org/healthprofessional/cancer-statistics/statistics-by-cancer-type/bowelcancer/survival\#heading-Three [Accessed August 8, 2020].

2 Cancer Research UK. Oesophageal cancer statistics. oesophageal cancer survival, 2017. Available: https://www.cancerresearchuk. org/health-professional/cancer-statistics/statistics-by-cancer-type/ oesophageal-cancer\#heading-Two [Accessed August 20, 2020].

3 Barwick TW, Scott SB, Ambrose NS. The two week referral for colorectal cancer: a retrospective analysis. Colorectal Dis 2004;6:85-91.

4 Gibbs JF, Rajput A, Chadha KS. The changing profile of esophageal cancer presentation and its implication for diagnosis. J Natl Med Assoc 2007;99:620-6.

5 Public Health England. National cancer intelligence network: routes to diagnosis 2015. Available: http://www.ncin.org.uk/publications/ routes to diagnosis [Accessed January 17, 2017].

6 Elliss-Brookes L, McPhail S, Ives A, et al. Routes to diagnosis for cancer - determining the patient journey using multiple routine data sets. Br J Cancer 2012;107:1220-6.

7 Smyth EC, Lagergren J, Fitzgerald RC, et al. Oesophageal cancer. Nat Rev Dis Primers 2017;3:17048.

8 National Institute of Clinical Excellence. Suspected cancer: recognition and referral. NICE guideline [NG12] UK 2015 [updated July 2017]. Available: https://www.nice.org.uk/guidance/ng12/ chapter/1-Recommendations-organised-by-site-of-cancer\#lowergastrointestinal-tract-cancers [Accessed May 21, 2020].

9 National Institute of Clinical Excellence. Suspected cancer:recognition and referral. NICE guideline [NG12] UK 2015 [updated July 2017]. Available: https://www.nice.org.uk/guidance/ ng12/chapter/1-Recommendations-organised-by-site-of-cancer\# upper-gastrointestinal-tract-cancers [Accessed August 20, 2020]

10 Adam ME, Fehervari M, Boshier PR, et al. Mass-Spectrometry analysis of Mixed-Breath, Isolated-Bronchial-Breath, and GastricEndoluminal-Air volatile fatty acids in esophagogastric cancer. Anal Chem 2019;91:3740-6.

11 Hanna GB, Boshier PR, Markar SR. Accuracy and methodologic challenges of volatile organic Compound-Based exhaled breath tests for cancer diagnosis: a systematic review and meta-analysis. JAMA oncology 2018:e182815 (published Online First: 2018/08/22).

12 Markar SR, Chin S-T, Romano A, et al. Breath volatile organic compound profiling of colorectal cancer using selected ion Flowtube mass spectrometry. Ann Surg 2019;269:903-10.

13 Markar SR, Wiggins T, Antonowicz S, et al. Assessment of a noninvasive exhaled breath test for the diagnosis of oesophagogastric cancer. JAMA Oncol 2018;4:970-6.

14 Markar SR, Brodie B, Chin S-T, et al. Profile of exhaled-breath volatile organic compounds to diagnose pancreatic cancer. Br J Surg 2018;105:1493-500.

15 Durán-Acevedo CM, Jaimes-Mogollón AL, Gualdrón-Guerrero $\mathrm{OE}$, et al. Exhaled breath analysis for gastric cancer diagnosis in Colombian patients. Oncotarget 2018;9:28805-17.

16 Tognoni G, Alli C, Avanzini F, et al. Randomised clinical trials in general practice: lessons from a failure. BMJ 1991;303:969-71.

17 Bell-Syer SEM, Thorpe LN, Thomas K, et al. Gp participation and recruitment of patients to RCTs: lessons from trials of acupuncture 
and exercise for low back pain in primary care. Evid Based Complement Alternat Med 2011;2011:1-7.

18 Foy R, Parry J, McAvoy B. Clinical trials in primary care. BMJ 1998;317:1168-9.

19 O'Dowd T. Research in general practice: who is calling the tune? $\mathrm{Br} \mathrm{J}$ Gen Pract 1995;45:515-6.

20 Braun V, Clarke V. Using thematic analysis in psychology. Qual Res Psychol 2006;3:77-101.

21 National Institute of Health Research. Faecal immunochemical testing (fit) for adenoma surveillance. fit for follow-up: National Institute of health research, 2019. Available: https://www. journalslibrary.nihr.ac.uk/programmes/hta/0922192\#/ [Accessed February 3, 2019].

22 Cross AJ, Wooldrage K, Robbins EC, et al. Faecal immunochemical tests (fit) versus colonoscopy for surveillance after screening and polypectomy: a diagnostic accuracy and cost-effectiveness study. Gut 2019;68:gutjnl-2018-317297:1651-2.

23 Doran SLF, Romano A, Hanna GB. Optimisation of sampling parameters for standardised exhaled breath sampling. J Breath Res 2017;12:016007.
24 Romano A, Doran S, Belluomo I, et al. High-Throughput breath volatile organic compound analysis using thermal desorption proton transfer reaction time-of-flight mass spectrometry. Anal Chem 2018;90:10204-10.

25 Chin S-T, Romano A, Doran SLF, et al. Cross-platform mass spectrometry annotation in breathomics of oesophageal-gastric cancer. Sci Rep 2018;8:5139.

26 Romano A, Hanna GB. Identification and quantification of VOCs by proton transfer reaction time of flight mass spectrometry: an experimental workflow for the optimization of specificity, sensitivity, and accuracy. J Mass Spectrom 2018;53:287-95.

27 Honkasalo MT, Linna M, Sane T, et al. A comparative study of two various models of organising diabetes follow-up in public primary health care - the model influences the use of services, their quality and costs. BMC Health Serv Res 2014;14:26.

28 Vedsted P. [Gender differences in the use of health care system]. Ugeskr Laeger 2007;169:2403-8.

29 Jørgensen JT, Andersen JS, Tjønneland A, et al. Determinants related to gender differences in general practice utilization: Danish diet, cancer and health cohort. Scand J Prim Health Care 2016;34:240-9. 